\title{
The Ukrainian longitudinal monitoring survey: towards a better understanding of labor markets in transition
}

\author{
Hartmut Lehmann ${ }^{1,2^{*}}$, Alexander Muravyev ${ }^{3,2}$ and Klaus F Zimmermann ${ }^{2,4}$
}

\author{
* Correspondence: hartmut. \\ lehmann@unibo.it \\ 'Department of Economics, \\ University of Bologna, Strada \\ Maggiore 45, Bologna 40125, Italy \\ ${ }^{2}$ Institute for the Study of Labor \\ (IZA), Bonn, Germany \\ Full list of author information is \\ available at the end of the article
}

\begin{abstract}
The paper presents the Ukrainian Longitudinal Monitoring Survey (ULMS), which is one of the most widely used household and labor force surveys in Eastern Europe. It is based on a statistically representative sample of the Ukrainian population aged between 15 and 72 years, comprising about 4,000 households and 8,500 individuals. The paper introduces the essential aspects of the ULMS, including sampling, survey instruments and content as well as discusses the current available data. Key details of the forthcoming 2012 wave of the survey are outlined. The article also provides an overview of major studies accomplished with the help of the ULMS data. The review suggests the usefulness and high potential of the survey in tackling important questions in labor economics and related fields.

JEL codes: $\mathrm{C} 83, \mathrm{~J} 00, \mathrm{P} 20$

Keywords: Survey panel data, Public use data, Transition, Ukraine
\end{abstract}

\section{Introduction}

The transition from plan to market which we have witnessed in Central and Eastern Europe from the late 1980s has sparked considerable interest among academics. It is now widely agreed that this transformation entailed important lessons and provided valuable contributions to mainstream economics (e.g., Ellman 2012). One of the essential elements of the reform, which drew particular attention, has been the transformation of labor markets in transition countries (Svejnar 1999). Labor economics benefited not only from the broad reform agenda pursued by these countries (e.g., Gorodnichenko et al. 2009; Danzer 2012), but also from the interpretation of the entire transition process in terms of a natural experiment (Christev, Kupets, and Lehmann 2008; Muravyev 2008).

The growing interest in labor markets in transition economies initially faced considerable data constraints. Individual and household surveys that were administered during the period of central planning and early transition years were inadequate to the needs of both policy-makers and researchers. As a response, several initiatives to collect data from the region were commenced both within government agencies and by independent research centers. Examples of data collection by independent research centers include the Russian Longitudinal Monitoring Survey (RLMS-HSE) for Russia (see RLMS-HSE 2012 for dataset description and Gibson et al. 2008 for 
example of analysis), the Rural-Urban Migration in China (RUMiC) panel data for China (see RUMiC 2008 for dataset description and Akay et al. 2012 for example of analysis) and the very recent "Life in Kyrgyzstan" panel survey for the Kyrgyz Republic (see Brück et al. 2012).

While data collection projects started in earnest in the early 1990s, mostly in Central Europe, and in some CIS countries ${ }^{1}$, Ukraine long remained a virtual terra incognita for students of labor markets. This is surprising in view of at least three facts. First, Ukraine is the second largest transition country having a territory larger than Metropolitan France and a population of 48.5 million (as of 2001 census) and is also bordering the European Union (since 2004). Second, the transition process in Ukraine was characterized by an extremely large initial shock and a fairly slow recovery. The country's real GDP declined by more than $60 \%$ in the 1990 s and has not reached the pre-transition level since then. Third, in addition to its large size in terms of territory and population, Ukraine is characterized by considerable regional diversity, including the well-known divide along ethnic and linguistic lines that became particularly pronounced since the 2004 Orange revolution.

In order to have a sound data base for the study of labor market issues central to the transition from Communism to a market-oriented social democracy in the second largest transition economy of Central and Eastern Europe, the program area "Labor Markets in Emerging and Transition Economies" of the Institute for the Study of Labor (IZA) spearheaded an effort to establish a panel household survey in Ukraine. In the first phase of this project, leading to the first two waves of the survey in 2003 and 2004, IZA led a scientific consortium with the other members being the William Davidson Institute of the University of Michigan, the Centre for Economic Reform and Transformation (CERT) of Heriot-Watt University, Edinburgh, and the Rheinisch-Westfälisches Institut für Wirtschaftsforschung in Essen (RWI-Essen). Data collection was entrusted to the Kiev International Institute of Sociology (KIIS). The project received the name of Ukrainian Longitudinal Monitoring Survey (ULMS) and was launched in 2003. The sample of the first wave in 2003 consisted of more than 8600 respondents, which is comparable to the initial samples of the American Panel Study of Income Dynamics (PSID), the German Socio-Economic Panel (SOEP), the British Household Panel Studs (BHPS) and the RLMS. Collection of the third wave of the ULMS in 2007 was sponsored by IZA, DIW Berlin and the European Union. Thus, three waves have been collected; in 2003, 2004, and 2007. Currently, the data for the 2012 wave are being collected as a joint effort of IZA and the World Bank.

The purpose of this article is two-fold. First, it describes the content and structure of the ULMS with regard to sample design, survey instruments, data access and user support, including essential information about the 2012 wave. Second, it reviews some of the studies which were based on the ULMS data to illustrate the appropriateness and richness of the data to address research and policy issues important not only in the context of Ukraine's transition, but also more generally. We hope that our paper can inspire many further high quality studies of the Ukrainian transition process.

The remainder of the article is organized as follows. Section 2 presents details on sampling, survey instruments, and content of the survey. Section 3 describes the available data. Section 4 provides a selective review of ULMS-based studies. Section 5 concludes. 


\section{Survey method}

\subsection{Sample}

The intial ULMS sample was created by the Kiev International Institute of Sociology (KIIS). The sample was drawn from the December 2001 Ukrainian Census and stratified by age, gender, city/town, and regional structure. The target of the household survey is the working age population. In the original ULMS sample in 2003, the definition of the working-age population pertained to persons between the ages of 15 and 72 , to whom the individual questionnaire was administered. Before the individual interviews took place, a household questionnaire was directed to the household head, taken as the person most knowledgeable of household matters. The fieldwork in 2003 lasted 3 months and was carried out by 160 interviewers.

The starting ULMS sample is representative for the working-age population of Ukraine in 2003, with 8,641 individuals in 4,055 households. Part of the sample (1,453 individual interviews, 841 households) had already been interviewed in two surveys on income, expenditure patterns and living conditions that KIIS had conducted for the World Bank in 1995 and 1996. These persons and households were included in the 2003 sample in order to study the dynamics of income and poverty in Ukraine (see, e.g., Brück et al. 2010). In this context, it is important to stress that the questionnaires administered in the 1995 and 1996 surveys were of a more limited scope than the questionnaires used in the 2003 ULMS survey ${ }^{2}$. The stratified sampling of the 2003 ULMS wave ensured that the total sample of interviewed individuals, consisting of the 1,453 previosuly surveyed individual respondents and the remaining 7,188 newly surveyed persons, as well as the total of 4055 households were statistically representative at the national level ${ }^{3}$. See (KIIS 2003) for a detailed description of the sample definition.

KIIS (2003) reports an initial household response rate of $66 \%$ for the ULMS. This is larger than the German SOEP Sample F household response rate of $60 \%$ in 2000 as reported by Haisken-DeNew and Frick (2005). The RLMS achieved an 84\% initial response rate in Round V (the starting sample of Phase II) of the representative RLMS, as reported by Heeringa (1997) with the lowest response rates coming from Moscow and St. Petersburg.

The attrition from wave 1 to wave 2 of the ULMS, being about 20\%, was comparable to that of the first wave of Sample F in the German SOEP in 2000-2001, where approximately $19 \%$ of the original 6,000 households left the sample after the first wave as shown by Haisken-DeNew and Frick (2005), who provide a complete overview of the sample development in the SOEP. In the 2002 Australian Household Income and Labor Dynamics of Australia (HILDA), 14\% of the households in wave 2 could not be surveyed. Much earlier from 1997 to 1998, in the Russian experience using the RLMS, the attrition rate was only $5 \%{ }^{4}$.

\subsection{The survey instruments}

The original questionnaires are available in English, Russian and Ukrainian. As in many household panel surveys, there are different reference periods addressed in the questionnaires: (i) retrospective questions, where information is gathered about employment changes in 1986, 1991, 1997, 1998-2002 and about changes of residence since 1986, and (ii) concerning the reference-week, where information is gathered about the week 
preceding the interview. Further, detailed individual characteristics of household members are collected, along with educational attainment and skills sections, and furthermore attitudes, health, and ecology issues.

The detail and depth of the ULMS data is similar to that of the German Socio-Economic Panel (GSOEP) and the British Household Panel (BHPS). The first wave of the ULMS, based on the individual questionnaire, includes 1,837 variables with an additional 679 variables in the life history chart. The data file based on the household questionnaire includes 240 variables. The average durations of interview were 72 and 22 minutes for the individual and the household surveys respectively. There are some particularly interesting aspects of the questionnaires. There is particular depth of information with respect to the respondent's own educational attainment and that of his parents. The retrospective questions concerning past labor market activity are asked in 2003 for the month of December of 1986, 1991, and 1997. These years are important landmarks in Ukraine history. In 1986, the Chernobyl catastrophe happened, the year of 1991 was the year of Ukraine's independence, and the year of 1997 marks the end of the first phase of the country's transition to a market economy (Dabrowski et al. 1999). Starting with January 1998, the retrospective questions elicit information on employment, unemployment and inactivity spells that last at least one month, permitting the recreation of a complete history of labor market states up to the date of the interview in $2003{ }^{5}$. Indeed these histories are so complete that hazard rate models can be run on labor market status. This is unusual since most household panels only collect current month information on labor market status.

As informal activity in the underground economy also plays an important role in Ukraine, contingent employment and informal employment are explicitly captured with the survey instrument. For dependent employees the relevant question asks whether a job is registered with the authorities, i.e. whether the employer and the employee pay taxes and social security contributions, while for self-employed the survey enquires whether the activity is registered. The special feature of the section on informality consists in establishing whether the informal employment relationship is voluntary or involuntary for dependent employees. Only the RLMS has also this feature. During transition to a market economy, there are many large changes in the industrial structure observed in the post-Soviet countries, leading to labor reallocation on a large scale. The questionnaires allow the researcher to observe whether an employee has been displaced or quit voluntarily when separating from a job. Together with the identification of informal employment activity, a precise picture can be taken of the household responses at the micro level.

\subsection{The content and topics of the survey instruments}

The core of the survey is the individual questionnaire, which elicits detailed information concerning the labor market experience of Ukrainian workers. The household questionnaire contains questions on the demographic structure of the household, its income and expenditure patterns, as well as living conditions. Individual survey data include primary and secondary employment, search activities, non-employment and participation in labor market programs in the reference week, education and skills, the ownership structure and its evolution at workers' firms, spatial mobility, health status, and political and environmental attitudes, wage arrears, payments in kind, 
unpaid leave, etc.; an extensive retrospective part tracks workers' labor market involvement at specific points in the past.

In the 2003 individual questionnaire there is an extensive retrospective section, which ascertains each individual's labor market circumstances beginning at specific points in time chosen to try to minimize recall bias (December 1986, just after Chernobyl, and December 1991, the end of the Soviet Union and December 1997).

Apart from sections that are standard in labor force surveys, there is an extensive retrospective part for the first wave, which tracks workers' labor market involvement at specific past points in time and which, as already stated, allows a complete reconstruction of workers' labor market histories between January 1998 and the reference week in 2003. For subsequent waves, there are retrospective sections that again allow the reconstruction of a complete history between the preceding and the current wave. In addition there are sections on education and skills, the ownership structure and its evolution at workers' firms, spatial mobility, health status and political and environmental attitudes. Finally, there is a large set of questions about wage arrears, payments in kind, unpaid leave etc. in order to address specific adjustment mechanisms that have taken place in Ukraine like in other labor markets of CIS countries. The ULMS provides arguably the most complete data source on labor market developments in any country of the CIS. Given the very rich data and their concentration on pertinent labor market issues, the 2012 panel element of the ULMS can be used as a unique instrument to assess the effect of the crisis.

After wave 1, the household questionnaire was expanded to incorporate several blocks of questions intended to measure household welfare. In particular, there is a detailed household consumption section similar to that used in the RLMS. This allows construction of consumption aggregates and estimation of welfare, inequality and poverty based on consumption rather than income, which is more appropriate for lower-middle income countries to which Ukraine currently belongs.

\subsubsection{Specific modules of the 2007 wave}

Two new modules were included in the 2007 individual survey, a module on the political attitudes of people in connection with the "Orange Revolution" as well as a module on risk and time preference attitudes of individuals. The set of questions in the module on political attitudes strives to generate a complete picture of the involvement of the residents of Ukraine in the "Orange Revolution", eliciting information on the participation and the motivation of respondents. They are also asked to reveal their political preferences, i.e. whether they endorsed the "Orange Revolution" or whether they were in the camp of the pro-Russia party around Yanukovich. In addition, they are asked about how they see the future political and economic prospects of Ukraine.

A few words are also in order about the second module. The module was designed after the risk and time preferences module developed in the GSOEP, using questions on risk attitudes that have been shown to elicit realistic answers regarding risk attitudes in a laboratory setting (see, e.g., Dohmen et al. 2011 and Bonin et al. 2012). Apart from questions related to general risk attitudes and domain specific risk attitudes, hypothetical lottery questions were also used since the resulting answers are often considered a good base for the development of a truly "objective" measure of risk attitudes.

Exploration of the 2007 data (Dohmen, Khamis and Lehmann 2010) provides some evidence of the complementary nature of the two types of questions eliciting responses 
on risk attitudes. The questions related to time preferences, on the other hand, have turned out to be too simplistic to overcome the bias known in the literature as the "bias of immediate consumption". This bias implies that most persons will always prefer to consume a good now than defer its consumption no matter how large the benefits of deferral. By giving respondents a choice between consumption in one month from now and consumption in 13 months this bias can be reduced substantially. Since the risk and time preferences module was included, in modified form, in the 2012 individual survey two advances on the 2007 data could be introduced. First, with the 2012 wave panel data regarding risk attitudes and time preferences will become available. Second, the questions on time preferences have been phrased in two ways: first, giving the consumption choice described above, and second, giving a choice between immediate consumption and consumption 12 months from now (as was done in the 2007 wave). As already stated, the first set of offered choices will reduced the immediacy bias substantially, whilst comparing the outcomes connected to the two sets of offered choices will allow researchers to establish the extent of this bias.

\subsubsection{Design of the 2012 wave}

Wave 4 of the ULMS, currently under way, is a joint project of IZA and the World Bank. The survey is a combination of the original ULMS and the World Bank STEP ${ }^{6}$ Survey (World Bank 2012), which in addition to Ukraine, is implemented in seven other countries in Africa, Asia, and Latin America. As a result of merging the ULMS and STEP modules, both survey sample and instruments have been modified as compared with the 2007 version of the ULMS. However, the continuity of the panel is carefully managed. The major scope of the World Bank STEP project is the gathering of information on cognitive and non-cognitive skills demanded by firms and supplied by the workforce. The ULMS 2012 survey instrument, asking this information on the supply side, thus has many segments from the original STEP survey instruments that hone in on skills. The merged ULMS-STEP survey instrument consists of three questionnaires: (i) the merged household questionnaire/roster, including the first block of STEP; (ii) the standard individual questionnaire, including the fifth block of STEP and some parts of the second, third and fourth blocks of STEP; (iii) and the extended individual questionnaire, which has an additional module on employment skills as well as reading exercises developed by the Educational Testing Service (ETS), Princeton, New Jersey.

The first questionnaire therefore collects information on the household; the extended individual questionnaire is administered to one randomly selected adult member of each surveyed household. The standard individual questionnaire is administered to the remaining adult household members. This survey design achieves thus two aims. It preserves the ULMS panel and it provides an extremely rich data set on cognitive and non-cognitive skills of Ukrainian workers. One of the unique features of the 2012 ULMS data set consists in the fact that this very rich information on kills can be linked to the labor market history of those workers who are in the panel, i.e. to the large majority of respondents.

In wave 4, the sample of the existing ULMS panel is augmented to meet the statistical requirements of both the ULMS and the STEP questionnaires. For the ULMS this means that the new sample is statistically representative at the national level, while for STEP, the requirement is fulfilled that the survey has at least 2,400 responding urban 
households and is at least representative of the urban population. The main blocks in the household and individual parts of the ULMS are described in Tables 1 and 2 . Table 1 shows the main blocks in the household questionnaire by wave. All waves collect detailed information about the structure of households, including the demographics and the relationship between household members. All waves also provide essential information on housing conditions of participating households as well as on total household income and its particular components. There are some differences across the waves, though. In comparison to all subsequent waves, wave 1 had a rather short consumption section, covering only the most essential food and non-food items. The section was enlarged in 2004 so that a standard consumption aggregate could be constructed from the data. The third wave had even greater detail and included new sections on saving and borrowing as well as on transfers and remittances. The fourth wave essentially repeats the second one, although some new questions from the STEP survey are added and the composition of sections changes. Overall, the data set is becoming richer over time with no evidence of major statistical defects due to changes in the survey instrument.

Table 2 shows the content of the individual part of the survey by wave. Waves 1 to 3 are similar with respect to the core part of the questionnaire. In wave 3, two additional topics were added, one on presidential elections in 2004 (the "Orange revolution"), and the other one on maternity and fertility. Thanks to the influence of STEP, the fourth wave considerably extends the set of questions on skills and also adds a reading exercise module. Again, the data set is becoming richer over time with no evidence of major statistical defects due to the changes from one wave to another.

\section{Available data}

3.1. Sample sizes and attrition, ULMS 2003, 2004, 2007

The survey was started in 2003 with 4,055 households and 8,641 individuals. Of the 4,055 households sampled in 2003, 430 appeared in the survey only once. Of the initial 8,641 individuals, 1,203 appear in the survey only once. In the 2004, there are also 57 new individuals entering the survey (new members of old households). This implies an attrition rate of about $14.5 \%$. Note, however, that some of the individuals that dropped from the 2004 survey reappeared in 2007. Thus, the actual attrition in the panel is smaller. Moreover, one should also take into account the fact that, as the ULMS was

Table 1 Main blocks in the household questionnaire by wave

\begin{tabular}{|c|c|c|c|c|}
\hline Block of questions & ULMS 2003 & ULMS 2004 & ULMS 2007 & ULMS 2012 \\
\hline Structure of household & $x$ & $x$ & $x$ & $x$ \\
\hline Housing Conditions & $x$ & $x$ & & $x$ \\
\hline Household Assets, Income and Expenditures & $X$ & & & $x$ \\
\hline Household Assets and Income & & $X$ & & \\
\hline Household expenditures & & $x$ & $x$ & $x$ \\
\hline Housing Conditions and Household Assets & & & $x$ & \\
\hline Land Use and Home Production & & & $x$ & \\
\hline Household Income & & & $x$ & \\
\hline Saving and Borrowing & & & $x$ & \\
\hline Transfers and Remittances & & & $x$ & \\
\hline
\end{tabular}


Table 2 Main blocks in the individual questionnaire by wave

\begin{tabular}{|c|c|c|c|c|}
\hline Block of questions & ULMS 2003 & ULMS 2004 & ULMS 2007 & ULMS 2012 \\
\hline Main job and second jobs in the reference week & $x$ & $x$ & $x$ & $x$ \\
\hline Unemployment and job seeking in the reference week & $x$ & $x$ & $x$ & $x$ \\
\hline Main jobs in 1986, 1991, 1997, 1998-2003 & $x$ & & & \\
\hline Non-employment in 1986, 1991, 1997, 1998-2003 & $x$ & & & \\
\hline Main jobs since the last wave & & $x$ & $x$ & $x$ \\
\hline Non-employment since the last wave & & $x$ & $x$ & $x$ \\
\hline Education and skills & $x$ & $x$ & $x$ & \\
\hline Skills & & & & $x$ \\
\hline Studies and skills & & & & $x$ \\
\hline Employment skills & & & & $x$ \\
\hline Changes of residence in 1986-2003 & $x$ & & & \\
\hline Changes of residence since the last wave & & $x$ & $x$ & $x$ \\
\hline Attitudes, health, and ecology & $x$ & $x$ & & \\
\hline $\begin{array}{l}\text { Attitudes, expectations, health, ecology and the } \\
\text { Presidential elections in } 2004\end{array}$ & & & $x$ & \\
\hline Attitudes, expectations, health and contact & & & & $x$ \\
\hline Section for women only. Maternity history & & & $x$ & \\
\hline EST Reading Exercises (STEP module) & & & & $x$ \\
\hline
\end{tabular}

designed as a labor force survey, it does not interview respondents older than 72 . This implies that a part of the attrition is imposed by the sampling rules. In particular, between 2003 and 2004, 106 out of 8,641 respondents (or 1.2\%) were dropped because their age exceeded the limit of 72 years. This is twice as large as individual sample attrition due to death (52 cases), according to the ULMS technical report (KIIS 2004).

Overall, 4,232 households and 9,902 individuals participated in the survey for 2003, 2004 and 2007. Of these, 2,705 households and 5,091 individuals appeared in all three waves, 2003, 2004, and 2007. Tables 3 and 4 provide a somewhat better idea about the composition of the panel. Symbols X mark the participation of households or individuals in a particular wave of the ULMS.

Note that there was no additional sampling of households in either 2004 or 2007. New households appear because of the split of old ones. New individuals in the survey may appear because of marriages, children becoming adults (and entering the survey at the age of 15), etc.

Table 3 Panel structure of the first three waves of the ULMS, households

\begin{tabular}{lccc}
\hline Wave 2003 & Wave 2004 & Wave 2007 & Observations \\
\hline 4,055 & 3,449 & 3,101 & 4,232 \\
$X$ & $X$ & $X$ & 2,705 \\
$X$ & $X$ & 0 & 689 \\
$X$ & 0 & $X$ & 231 \\
$X$ & 0 & 0 & 430 \\
0 & $X$ & $X$ & 43 \\
0 & $X$ & 0 & 12 \\
0 & 0 & $X$ & 122 \\
\hline
\end{tabular}


Table 4 The panel structure of the first three waves of the ULMS, individuals

\begin{tabular}{lccc}
\hline Wave 2003 & Wave 2004 & Wave 2007 & Observations \\
\hline 8,641 & 7,200 & 6,774 & 9,902 \\
$X$ & $X$ & $X$ & 5,091 \\
$X$ & $X$ & 0 & 1,868 \\
$X$ & 0 & $X$ & 479 \\
$X$ & 0 & 0 & 1,203 \\
0 & $X$ & $X$ & 184 \\
0 & $X$ & 0 & 57 \\
0 & 0 & $X$ & 1,020 \\
\hline
\end{tabular}

\subsection{Survey extensions}

The ULMS has collected geographical indicators at the oblast (region), rayon (county) and postal code level. The postal code data can be made available to users on an individual user basis only to ensure that data security concerns of potential re-identification are adequately addressed. In addition the detailed data on investment in skills and skill attainment as well as the reading exercises based on separate EST booklets, central to the STEP component of the 2012 ULMS wave, can be made available on an individual user basis only.

\subsection{Data access and user support}

The micro data for 2003, 2004, and 2007 are already available for use at the International Data Service Center of IZA (http://idsc.iza.org/ulms). It is foreseen that the 2012 wave will be made available at the end of 2014. The Data Service Center will provide the ULMS data to researchers free of charge as long as certain mild rules are followed. In particular, the Data Service Center of IZA will supply applicants with a data request form which collects information about

- the applicant of the request;

- every single user of the data set connected to the request;

- an outline of the research project, which must be of an exclusively academic nature.

The researcher will then revceive the data as long as she or he promises to inform the IDSC about any resulting publications. Data set inquiries should be made at idsc@iza.org. The data files themselves are available as binary distributions for Stata and SPSS. The data contain English labels, and are encrypted and stored as compressed archives. Code books for the waves 2003, 2004 and 2007 as well as technical reports on the waves facilitate the use of the data. The actual questionnaires used in the field, available in Ukrainian, Russian and in English, are also available for download. A bibliographical list, including abstracts, and a copy of all working papers using the ULMS are available for download to researchers working with the data. This ensures maximal interaction between ULMS users and provides the basis for re-analysis.

\section{Overview of studies based on ULMS data}

This section provides a review of major studies based on ULMS data. While the list of articles is by no means complete, it gives an idea of the breadth of topics that can be 
investigated using the ULMS. A particularly interesting aspect that is noticeable in this review is the high degree of compatibility of the ULMS with similar surveys, which has led to its active use in cross-country studies.

One of the topics that drew considerable attention is the returns to schooling during the transition from central planning to a market economy. The ULMS data lend themselves especially well to the analysis of returns to schooling since they are of high quality and since one can generate hourly wages. Before transition the countries of the region were characterized by considerable wage compression and a quite egalitarian distribution of income (Münich et al. 2005). This started to change in the early 1990s. The paper by Gorodnichenko and Sabirianova Peter (2005) contrasts the experiences of Russia and Ukraine, the largest countries of the region that had different experiences of economic reform. Based on the retrospective data from the RLMS and ULMS, they find increasing returns to education in both countries during the transition, albeit considerably higher in Russia than in Ukraine. Using modern decomposition techniques, the authors conclude that the difference in the returns to schooling between the two countries is largely due to the prices that workers characteristics command rather than to the differences in unobservables and in labor force composition. These sophisticated decomposition techniques can be undertaken because in both the RLMS and the ULMS data about worker characteristics are very detailed.

Terrell and Ganguli (2006) focus on the effect of institutions and markets on men's and women's wage inequality in Ukraine between 1986 and 2003, taking advantage of the ULMS retrospective section. Since this section has not only good wage data but is also very rich in workers' characteristics and labor market outcomes, the authors can use techniques tracing the evolution of inequality that are mainly employed in OECD countries. The paper documents a considerable rise in inequality and attributes it to changes in wage premiums and unobservable characteristics. The authors suggest the important role of the minimum wage in mitigating the effects of market forces on wage inequality.

Other aspects of human capital accumulation are discussed by Jurajda and Terrell (2007) and Pagés and Stampini (2009). In particular, Jurajda and Terrell (2007) employ ULMS data in a cross-country study of the effect of human-capital endowment, inherited from the planned economy, on regional unemployment patterns in four transition economies. The section on educational attainment in the ULMS survey instrument generates information about all educational degrees acquired by a worker over time thus capturing human capital accumulation well. Experience and tenure, being other factors of human capital accumulation, can also be deduced from the individuals' histories in a precise way. Pagés and Stampini (2009) is another cross-country study involving three Latin American and three transition economies that assesses labor market segmentation across formal and informal salaried jobs and self-employment. They show that human capital is a good predictor of self-selection into a formal or informal job.

Different aspects of unemployment are studied by Kupets (2006) and Lehmann, Pignatti and Wadsworth (2006). Kupets (2006) analyzes determinants of unemployment duration in Ukraine, a largely unexplored area in the transition context. She bases her analysis on the complete labor market histories of the years 1998 - 2002 that enable her to construct continuous unemployment spells. Having these spell data she then estimates a Cox proportional hazards model with two competing risks. The author 
finds that the total time in unemployment is significantly related to an individual's age, marital status, level of education, income while unemployed, and local demand constraints. The results suggest positive duration dependence of the hazard to employment until 14 months and negative duration dependence afterwards.

Lehmann et al. (2006) focus on the effects of economic transition on the pattern and costs of worker displacement in Ukraine, using retrospective information in the Ukrainian Longitudinal Monitoring Survey (ULMS) for the years 1992 to 2002. The analysis of the incidence and costs of diplacement in the Ukrainian labor market can be accomplished because of at least three features of the data. First, answers are collected on the reason for job separation, enabling the researcher to discriminate sharply between voluntary quits and displacement. Second, complete labor market histories permit hazard rate analysis upon displacement. Third, reliable time series of wages make it feasible to establish the causal effect of displacement on wages. Displacement rates in the Ukrainian labor market average between 2.8 and 5.1 percent of employment, roughly in line with levels typically observed in several Western economies. The risk of displacement was spread broadly across the population through both recession and growth periods. Around one third of displaced workers find re-employment without essentially interrupting employment while the majority lingers on in long-term non-employment. The wage costs of displacement for the sub-sample of displaced workers who find re-employment do not seem to be large. The main cost for displaced workers in Ukraine consists in the extremely long non-employment spell that the average worker experiences after layoff.

Brown, Earle, and Vakhitov (2006) take advantage of the detailed employee and employer characteristics available in the ULMS to study the effect of privatization on employment and wages. Using retrospective information, the authors are able to construct time series of employment and wages at each employer of each respondent. Such tracking of employees and employers allows observing employee-employer matches before and after privatization, which is extremely useful in addressing potential biases arising from the selection on the part of both firms (into ownership type) and workers (into employers of different types). The results suggest that privatization cuts the layoff probability in half, but also reduces wages. The analysis also documents differences by type of private ownership. In particular, outside investor ownership, while reducing separations more than insider ownership, leaves wages unaffected. Privatization also appears to benefit higher skilled employees of larger firms.

Gorodnichenko and Sabirianova Peter (2007) use the ULMS to obtain the first systematic measure of bribery using micro-level data. The study identifies the size of unobserved (unofficial) compensation, such as bribes of public sector employees using the compensating differential framework and the estimated sectoral gap in reported earnings and expenditures. The analysis is helped by the very detailed income and expenditure data collected in ULMS 2003 and ULMS 2004. In the case of Ukraine, the wages of public sector employees turn out to be between one-quarter to one-third less than of their private sector counterparts, with increasing differences at the top of the wage distribution. However, both public and private sector workers have similar levels of consumer expenditures and asset holdings. The authors interpret this fact as evidence of unofficial compensation in the public sector. They also estimate the lower bound of the extent of bribery in Ukraine at the level of $0.9-1.2 \%$ of the country's GDP. 
Brück et al. (2010) focus on determinants of poverty comparing two different periods of Ukraine's economic transition - the recession of the 1990s and the recovery of the mid-2000s. The analysis takes advantage of the extensive household consumption data available in the 2004 wave of the ULMS as well as of the similarity of the household data from the ULMS to the pre-ULMS survey held in Ukraine in 1995-96. The authors report that poverty in both periods follows some of the correlates typically found in the literature, including greater poverty among households with children and with less education. In the earlier phase of transition, poverty had some specific features including the relatively low importance of unemployment and the existence of poverty even among households with employment.

The study by Lehmann and Wadsworth (2011) takes advantage of the richness of the ULMS data to examine the extent of any long-lasting effects of exposure to the Chernobyl disaster on the health and labor market performance of the adult workforce. This richness consists in a gamut of self-reported health conditions as well as in reliable data on labor market outcomes and wages over time. Data on the local area level of radiation fallout from the Chernobyl accident in 1986, collected by the European Union, is used in conjunction with the ULMS data in the analysis. Variation of this radiation fallout is considered as a random exogenous shock with which the authors try to establish its causal impact on poor health, labor force participation, hours worked, and wages. They find a significant positive association between local area-level radiation dosage and perception of poor health, though much weaker associations between local area-level dosage and other specific self-reported health conditions. There is also some evidence to suggest that those who lived in areas more exposed to Chernobyl-induced radiation have significantly lower levels of labor market performance 20 years on.

Danzer (2012) uses quasi-experimental conditions stemming from doubling the legal minimum pension in Ukraine to study various aspects of labor supply among the elderly. In particular, the author exploits an unusually simple eligibility rule for state pensions to identify the income effect of labor supply. The analysis, based on the use of the differencein-differences estimator, regression discontinuity techniques as well as instrumental variable methods, suggests a retirement semi-elasticity of 0.1-0.2 with men and women responding at different margins, but with similar overall effect on labor supply.

Two recent papers by Constant, Kahanec and Zimmermann $(2011,2012)$ look at the effect of ethnic and linguistic diversity on earnings and political preferences. The first paper studies significant political and economic tensions between ethnic Russians and Ukrainians unveiled by the Orange Revolution in Ukraine. In particular, the authors raise the question whether this divide stemmed from purely ethnic differences or from ethnically segregated reform preferences. Using ULMS data collected prior to the revolution they find that voting preferences for the forces of the forthcoming Orange Revolution were strongly driven by preferences for political and economic reforms, but were also independently significantly affected by ethnicity; namely language and nationality. Russian speakers, as opposed to Ukrainian speakers, were significantly less likely to vote for the Orange Revolution, and nationality had similar effects. The second paper employs ULMS data and the Oaxaca-Blinder decomposition of earnings, to investigate differences in earnings between ethnic Russians and Ukrainians throughout Ukraine's transition era. A persistent and increasing labor market divide is documented. They authors find that language, rather than nationality, is the key factor behind an ethnic premium favoring Russians. 
Other important studies based on ULMS data include the analysis of fertility and family formation in Perelli-Harris (2008), of affordability of utility payments in Fankhauser, Rodionova and Falcetti (2008), and of alcohol consumption in Avdeenko, Bozzoli and Brück (2010). Lehmann et al. (2012) is a cross-country study of worker displacement comparing the experiences of Russia and Ukraine. Dohmen, Khamis, and Lehmann (2010) take advantage of the risk measures available in the ULMS-2007 to link risk attitudes and the incidence of informality among Ukrainian workers, while Akay and Khamis (2012) show the persistence of informal employment in the Ukrainian labor market.

\section{Conclusions}

In this paper we have presented an exciting panel data set, the Ukrainian Longitudinal Monitoring Survey (ULMS), which was developed within IZA's program area "Labor Markets in Emerging and Transition Economies". The ULMS data, which can be used by any researcher anywhere in the world free of charge, so far has three waves, collected in 2003, 2004, 2007, whilst a fourth wave is being collected at the time of writing. Sampling weights are provided in all four waves so that researchers can derive estimates that are statistically meaningful and nationally representative.

The ULMS data set is extremely rich since it has a nearly exhaustive coverage of topics regarding all major areas of conventional labor market analysis. The large changes that often can be observed in the data of transition economies imply that researchers can explore central topics in labor economics within the context of quasi-natural experiments. Because of its richness, the ULMS data lend themselves particularly to such explorations. The ULMS survey instruments also contain specific blocks of questions and modules that allow undertaking research on issues that are particularly pertinent in emerging and transition economies, like, e.g., the effects of large-scale privatization on the labor market, wage arrears, the depreciation of human capital acquired under communism, the evolution of the position of women in the labor market during transition as well as the peculiar nature of informality. It should also be stressed the the many cross-country studies for which the data set was used point to the comparability and high quality of the ULMS data.

The ULMS data have particular features that might be copied in surveys in other transition and developing countries. Researchers might want to replicate the retrospective sections in the four waves that allow the reconstruction of a complete labor market history as well as of wage trajectories. The same can be said about the modules on risk attitudes and time preferences since both are important factors explaining household and individual behavior at the micro level. In addition, cognitive and non-cognitive skills are vital for economic development. A replication of the sections on these skills, which appear in ULMS 2012, seems, therefore, warranted for other transition and developing economies. Finally, the very detailed income and expenditure data collected at the household level in ULMS 2004 and ULMS 2007 allow sophisticated research on income inequality and poverty that should be extended to other countries at the same level of income and development.

An overview of major research papers published using the ULMS demonstrates the breadth of topics that can be covered when employing this data. We expect that in the future researchers will find the ULMS an even more important source of information 
for the analysis of labor markets in transition countries as well as for the testing of a wide range of general issues of labor economics.

\section{Endnotes}

${ }^{1}$ CIS stands for the Commonwealth of Independent States, which until recently included 12 out of 15 constituent republics of the former USSR, namely Armenia, Azerbaijan, Belarus, Georgia, Kazakhstan, Kyrgyzstan, Moldova, Russian Federation, Ukraine Tajikistan, Turkmenistan, and Uzbekistan with Georgia officially leaving the organization in August 2009

${ }^{2}$ Hence, only for a limited number of variables can a panel be constructed linking the surveys of 1995 and 1996 with the ULMS survey of 2003

${ }^{3}$ The sample is also statistically representative at the 5 "macroregions", that is for West, East, South, North and Center, as well as Kyiv City

${ }^{4}$ We do not provide attrition data for wave 3 as the data are not directly comparable with the first two waves due to the different spacing of the waves ( 3 years versus 1 year only)

${ }^{5}$ So, the 2003 survey instrument is such that we know what people did in the labor market in December of 1986, 1991 and 1997. In addition, we have a complete labor market history of each respondent from January 1998 to the reference week in 2003

${ }^{6}$ STEP stands for "Skills toward Employment and Productivity"

Competing interest

The IZA Journal of Labor and Development is committed to the IZA Guiding Principles of Research Integrity. The authors declare that they have observed these principles.

\section{Acknowledgements}

The authors thank the editor Jackeline Wahba, an anonymous referee, Nikos Askitas and Giorgios Tassoukis for very useful comments.

Responsible editor: Jackline Wahba

\section{Author details}

${ }^{1}$ Department of Economics, University of Bologna, Strada Maggiore 45, Bologna 40125, Italy. ${ }^{2}$ Institute for the Study of Labor (IZA), Bonn, Germany. ${ }^{3}$ Graduate School of Management, St. Petersburg University, St. Petersburg, Russia.

${ }^{4}$ University of Bonn, Bonn, Germany.

Received: 20 November 2012 Accepted: 19 December 2012

Published: 31 December 2012

\section{References}

Akay A, Khamis M (2012) The persistence of informality: evidence from panel data. Res Labor Econ 34:229-255

Akay A, Bargain O, Zimmermann KF (2012) Relative concerns of rural-to-urban migrants in China. J Econ Behav Organ 81:421-441

Avdeenko A, Bozzoli C, Brück T (2010) Legacy from the Transition?: Alcohol Consumption by Young Adults in Ukraine. ESCIRRU Working Papers 26, DIW. German Institute for Economic Research, Berlin

Bonin H, Constant AF, Tatsiramos K, Zimmermann KF (2012) Ethnic persistence, assimilation and risk proclivity. IZA J Migr 1:5

Brown JD, Earle JS, Vakhitov V (2006) Wages, layoffs, and privatization: evidence from Ukraine. J Comp Econ 34(2):272-294

Brück T, Danzer AM, Muravyev A, Weißhaar N (2010) Poverty during transition: household survey evidence from Ukraine. J Comp Econ 38(2):123-145

Brück T, Esenaliev D, Kroeger A, Kudebayeva A, Mirkasimov B, Steiner S (2012) Household Survey Data for Research on Well-Being and Behavior in Central Asia. Discussion Papers 1257. German Institute for Economic Research, Berlin

Christev A, Kupets O, Lehmann H (2008) Trade liberalisation and employment effects in Ukraine. Com Econ Studies 50 (2):318-340

Constant A, Kahanec M, Zimmermann KF (2011) The Russian-Ukrainian Political Divide. Eastern Eur Econ 49(6):97-110

Constant A, Kahanec M, Zimmermann KF (2012) The Russian-Ukrainian Earnings Divide. Econ Transit 20(1):1-35

Dabrowski M, Dekhtiarchuk M, Górski U, Kovalev P, Kuz'min Y, Sultan K (1999) From Fragile Stabilization to Financial Crisis. CASE - Center for Social and Economic Research, Warsaw-Kiev, Ukraine

Danzer A (2012) Benefit Generosity and the Income Effect on Labor Supply: Quasi-Experimental Evidence. The Economic Journal, forthcoming. doi:10.1111/ecoj.12006

Dohmen T, Khamis M, Lehmann H (2010) Risk Attitudes and the Incidence of Informality among Workers: Evidence from a Transition Country. ESCIRRU Working Papers 22. German Institute for Economic Research, Berlin

Dohmen T, Falk A, Huffman D, Sunde U, Schupp J, Wagner GG (2011) Individual risk attitudes: new evidence from a large, representative, experimentally validated survey. J Eur Econ Assoc 9(3):522-550 
Ellman M (2012) What Did the Study of Transition Economies Contribute to Mainstream Economics? RRC Working Paper Special Issue 2. Hitotsubashi University, Tokyo

Fankhauser S, Rodionova Y, Falcetti E (2008) Utility payments in Ukraine: affordability, subsidies and arrears. Energ Policy 36(11):4168-4177

Gibson J, Stillman S, Le T (2008) CPI bias and real living standards in Russia during the transition. J Dev Econ 87(1):140-160

Gorodnichenko Y, Sabirianova Peter K (2005) Returns to Schooling in Russia and Ukraine: a semiparametric approach to cross-country comparative analysis. J Dev Econ 33(2):324-350

Gorodnichenko Y, Sabirianova Peter K (2007) Public sector pay and corruption: measuring bribery from micro data. J Pub Econ 91(5-6):963-991

Gorodnichenko Y, Martinez-Vazquez J, Sabirianova Peter K (2009) Myth and reality of flat tax reform: micro estimates of tax evasion response and welfare effects in Russia. J Pol Econ 117(3):504-554

Haisken-DeNew JP, Frick JR (eds) (2005) The Desktop Companion to the German Socio-Economic Panel Study. German Institute for Economic Research, Berlin

Heeringa SG (1997) Russia Longitudinal Monitoring Survey (RLMS): Sample Attrition, Replenishment, and Weighting in Rounds V-VII. Mimeo, Ann Arbor, Michigan

Jurajda S, Terrell K (2007) Regional unemployment and human capital in transition economies. Econ Transit 17(2):241-274

KIIS (2003) Ukrainian Longitudinal Monitoring Survey 2003, Technical Report, Kiev International Institute of Sociology. Mimeo, Kiev

KIIS (2004) Ukrainian Longitudinal Monitoring Survey 2004, Technical Report, Kiev International Institute of Sociology. Mimeo, Kiev

Kupets O (2006) Determinants of unemployment duration in Ukraine. J Com Econ 34(2):228-247

Lehmann H, Wadsworth J (2011) The impact of Chernobyl on health and labour market performance. J Health Econ 30 (5):843-857

Lehmann H, Pignatti N, Wadsworth J (2006) The incidence and cost of job loss in the Ukrainian labor market. J Com Econ 34(2):248-271

Lehmann H, Muravyev A, Pignatti N, Zaiceva A (2012) Worker displacement in Russia and Ukraine: a comparative analysis using micro data. In: Brück T, Lehmann H (eds) In the Grip of Transition; Economic and Social Consequences of Restructuring in Russia and Ukraine. Palgrave Macmillan, pp 7-46

Münich D, Svejnar J, Terrell K (2005) Returns to human capital under the communist wage grid and during the transition to a market economy. Rev Econ Stat 87(1):100-123

Muravyev A (2008) Human capital externalities: evidence from the transition economy of Russia. Econ Trans 16(3):415-443

Pagés C, Stampini M (2009) No Education, no Good Jobs? Evidence on the Relationship between education and labor market segmentation. J Com Econ 37(3):387-401

Perelli-Harris B (2008) Family formation in post-soviet Ukraine: changing effects of education in a period of rapid social change. Soc Forces 87(2):767-794

RLMS-HSE (2012) The Russia Longitudinal Monitoring Survey - Higher School of Economics. Description of the Dataset, http://www.cpc.unc.edu/projects/rlms-hse

RUMiC (2008) Rural-Urban Migration in China. Description of the Dataset. http://idsc.iza.org/?page=86\&wid=778

Svejnar J (1999) Labor Markets in the Transitional Central and Eastern European Economies. In: Ashenfelter O, Card D (eds) Handbook for Labor Economics, vols 3-4. Elsevier Science, New York and Oxford, North-Holland, pp 2809-2857

Terrell K, Ganguli I (2006) Institutions, markets and men's and women's wage inequality: evidence from Ukraine. J Com Econ 34(2):200-227

World Bank (2012) STEP Skills Measurement Survey. World Bank, Washington, DC, http://siteresources.worldbank.org/ EXTHDOFFICE/Resources/5485726-1281723119684/STEP_Skills_Measurement_Brochure_Jan_2012.pdf

doi:10.1186/2193-9020-1-9

Cite this article as: Lehmann et al: The Ukrainian longitudinal monitoring survey: towards a better understanding of labor markets in transition. IZA Journal of Labor \& Development 2012 1:9.

\section{Submit your manuscript to a SpringerOpen ${ }^{\circ}$ journal and benefit from:}

- Convenient online submission

- Rigorous peer review

- Immediate publication on acceptance

- Open access: articles freely available online

- High visibility within the field

- Retaining the copyright to your article

Submit your next manuscript at $\boldsymbol{\sim}$ springeropen.com 